\title{
PAPPASENG TO MATOA DALAM MASYARAKAT BUGIS: KARAKTER PENDUKUNG BAGI MANUSIA
}

\author{
Sitti Annurwati Mutmainnah \\ Program Studi Bahasa dan Sastra Indonesia, Fakultas Sastra \\ Universitas Muslim Indonesia \\ stannurwati@gmail.com
}

\begin{abstract}
Abstrak
Pappaseng yang mengandung makna semantik pada kata 'saloe na dek uwaena' adalah simbol sungai yang tidak memiliki air. Air memiliki simbol kehidupan. Sungai identik dengan air sebagai sumber kehidupan, jika sungai itu akan merangas dan ditinggalkan oleh orang-orang yang di sekelilingnya. Pappaseng tersebut merupakan kesendiran terhadap pemimpin yang dapat menjadi sumber kesejahteraan rakyat, jika tidak memiliki sifat jujur maka rakyat akan hidup sengsara dan meninggalkannya. Fungsi lain pappaseng adalah untuk mengingatkan pemimpin agar bersifat amanah dalam memimpin. Dalam pappaseng disebutkan bahwa yang bermaksud bagian dari tiang dunia adalah raja atau pemimpin yang jujur, ulama yang suhud, orang kaya yang dermawan, dan orang miskin yang sabar. Kehiduan dalam dunia ini bisa tegak dan aman bila didukung oleh empat komponen tersebut. Bila salah satu dari mereka yang rusak, maka kehidupan di dunia ini akan terganggu. Fungsi pappaseng adalah sebagai sarana: (1) nasihat dan kritik, (2) karakter diri pada manusia, dan (3) nasihat dan sumber nilai. Pappaseng selain sebagai sarana pembentukan karakter juga menjadi sarana hiburan masyarakat Bugis.
\end{abstract}

Kata Kunci: Pappaseng, masyarakat Bugis, karakter

\section{PENDAHULUAN}

Setiap manusia pasti menyadari akan adanya karakter dalam kehidupan sehari-hari. Salah satu cara menanamkan pendidikan karakter adalah melalui apresiasi sastra ataupun sastra klasik, seperti Pappaseng yang berkembang dalam masyarakat suku Bugis di Sulawesi Selatan.

Karya sastra dapat membentuk kepribadian, karena di dalamnya memuat amanat tentang moral, mengembangkan imajinasi dan kreativitas. Sastra dapat digunakan untuk menanamkan, menumbuhkan, dan mengembangkaan kepekaan kepada siswa terhadap masalahmasalah dunia, pengenalan dan rasa hormat terhadap tata nilai, baik dalam konteks individu maupun sosial, yang kesemuanya itu sangat relevan dengan muatan yang terdapat dalam kurikulum pendidikan karakter di Indonesia (Mansyur, 2016).

Dalam pembentukan karakteristik, seseorang perlu memahami dengan baik mengenai pappaseng, perlu diketahui fungsi tepatnya dalam masyarakat bugis yang terlebih dahulu memahami teks ini. Pappaseng adalah pesan yag disampaikan secara lisan oleh orang-orang bijak dalam masyarakat Bugis terhadap raja yang berkuasa atau orang tua terhadap anakanaknya yang bertujuan membentuk karakter yang baik. Pappaseng dapat disampaikan secara langsung, dapat berupa kata kiasan atau sindiran untuk mengubah perilaku seseorang. Paseng atau 
pappaseng ditulis dalam lontarak yang disebut Surek Ugik.

Pappaseng adalah wasiat orang tua kepada anak cucunya (orang banyak) yang harus selalu diingat sebagai amanah yang perlu dipatuhi dan dilaksanakan atas dasar percaya pada diri sendiri disertai rasa tanggung jawab.

\section{PEMBAHASAN}

\section{Pappaseng sebagai Kritik Sosial}

Kearifan lokal Bugis banyak terdapat dalam pappaseng yang memuat beberapa nilai luhur yang berfungsi untuk sarana kritik atu sindiran terhadap ketimpangan dan penyelewengan atau kesewenangwenangan yang dilakukan oleh perintah raja, orang kaya. Kritik biasa dilakukan sebagai kontrol sosial terhadap perilaku seseorang, suatu kelompok tertentu yang menyimpan dari kebiasaan dan aturan sosial serta aturan hukum. Berikut beberapa kritik yang biasa dilakukan oleh bijak untuk kemaslahatan hidup orang banyak.

a. Kritik dan sindiran terhadap raja/pemerintahan:

Naia arung mangkauke nadek lempukna, padatoi barkna saloe nadek uwaena

Artinya: Raja/penguasa yang tidak jujur bagaikan sungai yang tidak berair.

Pappaseng tersebut mengandung makna semantik pada kata 'saloe na dek uwaena' adalah simbol sungai yang tidak memiliki air. Air memiliki simbol kehidupan. Sungai identik dengan air sebagai sumber kehidupan, jika sungai akan merangas dan ditinggalkan oleh orang-orang yang di sekelilingnya. Paseng tersebut merupakan kesendiran terhadap pemimpin yang dapat menjadi sumber kesejahteraan rakyat, jika tidak memiliki sifat jujur maka rakyat akan hidup sengsara dan meninggalkannya. Fungsi lain pappaseng untuk mengingatkan pemimpin agar bersifat amanah dalam memimpin.

Penguasa yang tidak jujur seperti sungai yang tidak berair, bermakna seorang pemimpin bila tidak jujur hanya memiliki nama pemimpin, namun tidak memberikan manfaat bagi rakyatnya. Bentuk kritikan pada paseng tesebut diatas masih sangat relevan dengan zaman sekarang yang masih banyak pemimpin tidak memiliki sifat jujur jika mendapat amanah dari rakyat. Eksistensi kepemimpinan dalam pappaseng tersebut yaitu dapat member kesejahteraan yang dipimpin.

b. Kritik dan sindiran terhadap orang kaya:

Naia tosugike nadek labona padatoisa ebarakna ellung maumpek nadek bosina.

Artinya: orang kaya tanpa sifat dermawan laksana awan tebal yang tanpa hujan.

Pappaseng tersebut terdapat kata 'ebarakana ellung maumpek', berupa klausa yang merupakan simbol awan tebal. Awal tebal memiliki makna harapan akan turun hujan. Hujan sebagai tanda akan memberikan kehidupan pada manusia karena menghidupkan tanaman dan tumbuhan. Awan tebal yang tidak menurunkan hujan mengecewakan banyak orang karena tidak mendapatkan manfaat dari keberadaan awan tebal. Simbol awan tebal tersebut dilekatkan pada orang kaya yang memiliki banyak harta. Orang kaya yang kikir tidak mendermakan hartanya pada orang yang membutuhkan sifat orang kaya tidak dermawan identik dengan awan 
tebal tanpa hujan. Tidak memberi manfaat pada orang banyak.

Orang kaya tidak dermawan laksana awan tebal tanpa menurunkan hujan. Artinya, orang kaya memiliki banyak harta, namun memberikan berkah bagi orang-orang dari sekelilingnya. Tidak mengeluarkan sedekah bagi orang miskin sehingga kekayaannya tidak dapat dinikmati oleh orang lain. Paseng tersebut mereferensikan ideology cultural yang memuat kritik terhadap orang kaya. Eksistensi kedermawaan adalah memberi sebagian harta kepada orang lain.

\section{Karakter pada Diri Manusia}

Karakter pada diri manusia memiliki banyak macam yang harus diketahui oleh setiap yang ingin mendalaminya, dalam pembagian karakter antara lain:

1. Deceng na jak (karakter baik dan buruk), terkaiat erat dengan perasaan tentang suka dan tidak suka pada sesuatu. Baik dan buruk adalah nilai sebuah perbuatan yang menjadi ukuran dari hasil perbuatan, atau sebuah pedoman perbuatan yang bisa dilakukan atau tidak bisa dilakukan. Nilai dilembagakan dalam karifan orang-orang tua terdahulu yang dilestarikan dalam bentuk paseng. Paseng dapat digolongkan sebagai karya sastra seperti halnya pantun, peribahasa dan elong.

2. Lempuk (karakter jujur), lempuk bermakna jujur. Kata jujur artinya lurus hati, tidak berbohong, tidak curang, dan ikhlas (KBBI IV, 2012;591). Karakter jujur (lempuk), alempureng (kejujuran) terkait dengan sifat seseorang yang tulus hati, tidak curang, ikhlas dalam interaksi dengan sesama manusia. Karakter jujur sangat dijunjung tinggi oleh masyarakat Bugis, seperti yang terungkap dalam beberapa data dalam pappasaeng tomatoa.

3. Warani (karakter berani), warani atau berani artinya sifat yang dimiliki pleh seseorang yang mau melakukan sesuatu perbuatan atau pekerjaan yang mengandung tantangan dan resiko. Banyak orang yang tidak mau menghadapi hal-hal mengandung resiko namun masih ada juga yang memiliki sifat menantang gelombang laut melakukan pelayaran untunk mengurangi samudera.

4. Ada na gauk (karakter sesuai kata dan perbuatan), bermakna kata dan perbuatan. Kata yang bermakna ucapan ada na gauk bermakna perilaku yaitu segala gerak-gerik sikap dan tingkah laku.

5. Marenreng perru (karakter setia), setia dari kata marenreng, secara etimologi bermankna bergetar, bergerak, dan perlu artinya usus, usus yang menghubungkan anak dan orang tuanya disebut ari-ari.

6. Sipakatau (karakter kemanusian), memanusiakan manusia, menghargai orang seperti menghargai diri sendiri. Sipakatau berasal dari kata dasar 'tau' yang berarti orang lain. Sipakatau bermakna pemberian kepada seseorang karena mereka berhak mendapatkannya seperti penghargaan, kasih-sayang, dan cinta.

7. Aseddi-seddingeng (karakter gotong royong), salah satu tema yang diungkap dalam pappaseng tomatoa adalah asedding-seddingeng (gotong royong) atau bekerja bakti. 
Kebijaksanaan sebagai Sumber Nilai

Kebijaksanaan hidup dapat diperoleh melalui nasihat terhadap diri, kritik terhadap masalah sosial.

\section{Kebijkasanaan Nasihat Berupa Ajaran}

Nasihat yang berupa ajaran memiliki cirri kalimat yang memberikan petunjuk tentang yang baik dan buruk.

Naia allirinna lino-e eppakki uangenna; seuani, arung melempuk-e, maduanna topanrita, bokoriengngi lino, bettuanna pakkisiwiannani ri allahu ta ala napogauk, matelluna, tossugik-e namalobo; mappaekna, pakerek-e, namasabbarak.

Artinya: dunia ini memiliki empat tiang: (1) raja atau penguasa yang jujur, (2) ulam ayang subud, (3) orang kaya lagi dermawan, dan (4) orang miskin yang sabar.

Pappaseng tersebut di atas terdapat simbol 'allirinna linoe'. Kata tiang selalu identik dengan penyanggah, penopang agar sesuatu yang disanggah bisa tegak. Dunia identik dengan kehidupan. Jadi bila diplesetkan dengan pengertian secara hakikat bahwa hidup ini bisa aman bila ada yang menopang. Dalam paseng disebutkan bahwa yang bermaksud bagian dari tiang dunia adalah raja atau pemimpin yang jujur, ulama yang suhud, orang kaya yang dermawan dan orang miskin yang sabar. Kehiduan dalam dunia ini bisa tegak dan aman bila didukung oleh empat komponen tersebut. Bila salah satu dari mereka yang rusak maka kehidupan di dunia ini akan terganggu.

Ajaran yang disampaikan dalam paseng tersebut adalah untuk mengetahui diri masing-masing bila menjadi manusia ditakdirkan oleh Allah sebagai salah satu dari pemimpin atau ulama sehingga kehidupan di dunia ini aman dan tentram.
Eksistensi kehidupan di dunia ini berjalan dengan aman, tentram dan damai apabila didkung oleh empat komponen yang kuat yaitu raja yang jujur, ulama yang suhud, kaya dan dermawan dan orang miskin yang sabar.

\section{Pandangan Bahasa dalam Pappaseng sebagai Kebudayaan Masyarakat Bugis}

Bahasa sebagai lambang mempunyai makna, dalam linguistik ilmu yang mempelajari makna disebut semantik. Secara tradisional, Ferdinand de Saussure telah mengemukakan bahwa dalam semantik terdapat tiga komponen, yaitu bentuk, makna (konsep) dan referen. Ketiga komponen ini biasa disebut segitiga penandaan (triangle of signification).

Hubungan bentuk berupa leksem atau kata sangat erat hubungannya dengan makna(konsep), demikian pula konsep dengan referen atau kenyataan, namun hubungan bentuk dengan referen tidak demikian. Hubungannya terjadi secara tidak langsung. Meskipun demikian, pemahaman bahasa, khususnya gaya dalam kaitannya dengan kebudayaan pada umumnya didasarkan atas perkembangan teori dan metode pemahaman bahasa yang lahir awal abad ke-20. Model Bahasa pada gilirannya digunakan dalam kaitannya dengan cirri-ciri retorika ilmu sosial humaniora, bahkan juga dalam ilmu pengetahuan pada umumnya. Menurut proposisi teoritis ini kenyataan dan kebenaran terbentuk sebagian dari praktik representasi dan interpresentasi, yaitu sebagai hubungan bahkan kesepakatan antara retor dan publik.

Kemampuan Manusia untuk berbahasa sangat penting. Diduga bahasa menjadi lebih berarti sejak ditemukannya sekaligus digunakannya bentuk tulisan. 
Sejak saat itulah ada alat kontrol untuk mengetahui perkembangan bahasa secara keseluruhan sekaligus berfungsi sebagai media dalam rangka membina kelas tariannya.

Secara garis besar telah disinggung kebudayaan didefinisikan sebagai keseluruhan hasil aktivitas manusia baik dengan nilai posistif maupun nilai negative. Akhir abad ke-20 dengan lahirnya era postmodernisme lahir pula lah kajian budaya secara khusus memberikan perhatian terhadap aspek-aspek yang muncul ke permukaan, ciri-ciri yang seolah-olah termarginaliskan, tetapi dalam kenyataannya memiliki peranan sangat menentukan.

Untuk melihat gaya dalam pengertian yang lebih umum, bukan semata-mata wilayah seni, perlu dikutip pendapat Hdjinicolau (1978:90) yang membedakan gaya menjadi tiga macam, sebagai berikut:

1. Gaya sebagai bentuk khusus pemakaian bahasa

2. Gaya sebagai memeiliki kekuatan artistik

3. Gaya sebagai cara pemakaian yang khas dan memiliki daya artistik yang sekaligus muncul dari masyarakat.

\section{Pappaseng To Riolo:}

1. Mauni coppo' bolana gurutta' riuja madorakamoni'

Artinya: walaupun bubungan atap rumah guru yang dicela, maka kita pun berdosa.

Fungsi: agar anak senantiasa menghormati gurunya.

Nilai: pendidikan akhlak.

2. Aja' muoppang nasaba matei mati indo'mu
Artinya: jangan engkau tidur tengkurap/meniarap, nanti mati ibumu.

Fungsi: supaya anak menghentikan kebiasaan yang merugikan dirinya yakni bisa berakibat sesak nafas.

Nilai : pendidikan kesehatan.

3. Narekko purani riaccinaungi passiring bolana tauwe tempeddinni rinawanawa maja

Artinya: kalau kita sudah berteduh di bawah atap rumahnya seseorang, sudah tidak boleh lagi dibenci (diusahakan ia binasa).

Fungsi: supaya anak tahu menghargai budi orang lain.

Nilai: pendidikan akhlak

4. Aja muleu ri tanae, konallekkaiko manu-manu mateitu indo'mu

Artinya: jangan kamu baring di tanah, karena kalau ada burung melewatimu ibumu akan mati.

Fungsi: supaya anak jangan mengotori dirinya.

Nilai : pendidikan kesehatan.

5. Aja muala aju pura rette' walie nakotenna iko rette'i, aja' to muala aju ripasanre'e, kotenna iko pasanrei

Artinya: jangan kau ambil kayu yang sudah dipotong ujung dan pangkalnya. Dan jangan pula engkau ambil kayu yang tersandar, kalau bukan kau yang sandarkan.

Fungsi: supaya anak tahu menghargai hak orang lain.

Nilai: pendidikan kejujuran.

6. Aja muinung tettong, malampei lasomu Artinya: jangan minum berdiri, nanti panjang kemaluanmu.

Fungsi: supaya gelas tidak jatuh/pecah. Nilai: memelihara keselamatan barang.

7. Aja munampui tanae, mataruko

Artinya: jangan menumbuk tanah, karena kamu bisa jadi tuli. 
Fungsi: supaya anak tidak mengotori dirinya sendiri.

Nilai : pendidikan kebersihan.

8. Ngowa na kellae, sapu ripale paggangkanna

Artinya: rakus dan tamak berakibat kehampaan.

Fungsi: supaya anak tahu mensyukuri yang ada (sedikit tapi halal).

Nilai: pendidikan untuk menghormati hak orang lain (tidak serakah)

9. Aja muanre tebbu ri leuremmu, matei indo'mu

Artinya: jangan makan tebu di tempat tidurmu, akan mati ibumu.

Fungsi: supaya anak tidak kotor dan dikerumuni semut.

Nilai : pendidikan kebersihan.

10. Ricau amaccangnge,

riabbiasangengnge

Artinya: kalah kepintaran dari kebiasaan atau pengalaman.

Fungsi: supaya anak rajin belajar.

Nilai: pendidikan kepatuhan.

11. Aja Muakkelong Riyolo Dapureng, Tomatowa Matu Muruntu'

Artinya: jangan menyanyi di muka dapur, jodohmu nanti orang tua.

Fungsi: supaya anak tahu menempatkan sesuatu pada posisinya masing-masing.

Nilai: pendidikan ketertiban.

12. Getteng lempu adatongeng

Artinya: tegas, jujur serta berkata benar.

Fungsi: supaya anak teguh pada pendirian,,jujur, dan berbudi bahasa yang baik.

Nilai: pendidikan mental.

13. Aja Mubuangi Sanru'e, Maponco Sunge tauwe.

Artinya: jangan menjatuhkan sendok, kita pendek umur.
Fungsi: supaya sendok tak jatuh kotor.

Nilai: pendidikan kebersihan.

14. Komuturusiwi Nafessummu, padaitu mutonanginna lopi Masebbo'E.

Artinya: kalau kamu menuruti nafsumu, sama saja engkau menumpang perahu bocor.

Fungsi: kalau tidak tahu mengendalikan diri, pasti binasa.

Nilai: pendidikan pengendalian diri (amarah).

15. Engkatu Ada Matarengngi Nagajangnge.

Artinya: ada perkataan lebih tajam dari keris.

Fungsi: supaya anak memelihara selalu bahasanya kepada orang lain.

Nilai: pendidikan akhlak.

16. Naiyya Balibolae, Padai Selessurengnge.

Artinya: adapun tetangga itu sama dengan saudara.

Fungsi: supaya kita menghormati tetangga.

Nilai: pendidikan akhlak dan kerukunan bermasyarakat.

17. Aja Mutudang risumpangnge, Mulawai dalle'E.

Artinya: jangan duduk di muka pintu, kau menghambat rezeki.

Fungsi: supaya anak tidak menghalangi orang yang mau lewat.

Nilai: pendidikan tata krama.

18. Rekko Mupakalebbi'i Tauwe, Alemutu Mupakalebbi.

Artinya: kalau kamu memuliakan orang, berarti dirimulah yang kau muliakan.

Fungsi: agar anak senantiasa memuliakan dan menghargai orang lain.

Nilai: pendidikan tata krama. 
19. Aja' Muasseringangngi Pale'mu, Sapu ripalekko.

Artinya: jangan jadikan sapu telapak tanganmu, nanti kamu hampa tangan.

Fungsi: supaya anak jangan mengotori tangannya, dan bisa kena benda tajam.

Nilai: pendidikan kebersihan.

20. Aja Mutudangiki angkangulungnge, malettakko.

Artinya: jangan menduduki bantal, nanti kau kena bisul.

Fungsi: agar anak tidak merusak alat tempat tidur.

Nilai: pendidikan untuk memelihara peralatan.

21. Anreo Dekke inanre, Namalampe Welua'mu.

Artinya: makanlah nasi yang hangus pada dasar periuk supaya panjang rambutmu.

Fungsi: membuat anak mau saja makan nasi yang tidak baik (hangus).

Nilai: pendidikan agar anak tidak mubazir.

22. Resopa Natemmangingngi, Malomo Naletei Pammase Dewata

Artinya: hanya kerja disertai ketekunan, mudah mendatangkan rezeki Tuhan.

Fungsi: agar anak tidak malu bekerja keras untuk mendapat rezeki.

Nilai: pendidikan kerajinan dan ketekunan.

23. Naiyya Olokolo'E Tuluna Riattenning, Naiyya Tauwe Adanna Riattenning.

Artinya: kalau binatang, talinyalah yang dipegang, kalau manusia perkataannya yang dipegang.

Fungsi: agar anak konsisten dapat menepati perkataannya.

Nilai: pendidikan kejujuran (akhlak).

24. Cicemmitu tauwe Tai ri lalengnge, Idi'na sini riaseng.
Artinya: sekali kita berak di jalan, maka kitalah yang selalu dituduh.

Fungsi: jangan sekali-kali kita berbuat yang tidak baik, karena selalu kitalah yang dituduh kalau ada perlakuan yang sama.

Nilai: pendidikan anak agar tidak berperilaku buruk.

25. Panni'na manue muanre, Malessiko lari.

Artinya: sayapnyalah ayam yang kau makan, jadinya kau kuat lari.

Fungsi: supaya anak tidak manja dalam memilih makan.

Nilai: pendidikan agar anak tidak membuat masalah terhadap makanan keluarga.

26. Aja murennuangngi anu dee ri limammu

Artinya: janganlah engkau terlalu mengharapkan apa yang belum ada pada tanganmu.

Fungsi: supaya tidak terlalu berani mengharapkan barang (uang) yang belum tentu didapat (hari) itu.

Nilai: peringatan agar tidak meremehkan janji, sampai salah jadinya

\section{KESIMPULAN}

Pappaseng adalah pesan yang disampaikan secara lisan atau tertulis dalam bentuk lontarak oleh orang-orang bijak dalam masyarakat bugis, atau orang tua terhadap anak-anaknya yang bertujuan membentuk karakter baik. Pappaseng berfungsi sebagai sarana: (1) nasihat dan kritik, (2) karakter diri pada manusia, dan (3) nasihat dan sumber nilai.

Selain sebagai sarana pembentukan karakter, pappaseng juga menjadi sarana hiburan masyarakat bugis. Pappaseng tersebut mereferensikan ideologi kultural 
yang memuat kritik terhadap orang kaya.

Eksistensi kedermawaan adalah memberi sebagian harta kepada orang lain.

\section{DAFTAR PUSTAKA}

Amin, K.F. (2015a). Pappaseng Ugik. Makassar: Garis Khatulistiwa. . (2015b). Sastra Klasik Bugis Makassar: De La Macca.

Koentjaraningrat. (2015). Pengantar Ilmu Antropologi. Rineka Cipta.

Mansyur, U. (2016). Pemanfaatan Nilai kejujuran dalam Cerpen sebagai Bahan Ajar Berbasis Pendidikan Karakter. In Mengais Karakter dalam Sastra: HISKI Makassar. https://doi.org/10.17605/OSF.IO/Z4T $3 \mathrm{Y}$
Mansyur, U. (2018). Peranan Etika Tutur Bahasa Indonesia dalam Pembelajaran di Sekolah. INA-Rxiv. https://doi.org/10.31227/osf.io/wrs9d Manyambeang, A.K. (2014). Syekh Yusuf dalam Perspektif Lontaraq Gowa. Badan Perpustakaan dan Asip Daerah Propinsi Sulawesi Selatan.

Ratna, N.K. (2014). Stilistika Kajian Puitika Bahasa, Sastra, dan Budaya. Pustaka Pelajar.

Seni Budaya. Kebudayaan Suku Bugis, (Online, https://ilmuseni.com/).

Syamsudduha. (2013). Pappaseng sebagai Falsafah Hidup, (Onliine) (http://syamsudduhaa. blogspot.co.id). 